\title{
THE
}

\section{FLYING MACHINE}

WALTZ

COMPOSED BY

\section{GEORGE L. O. DAVIDSON}

PRICE 2/6 NET
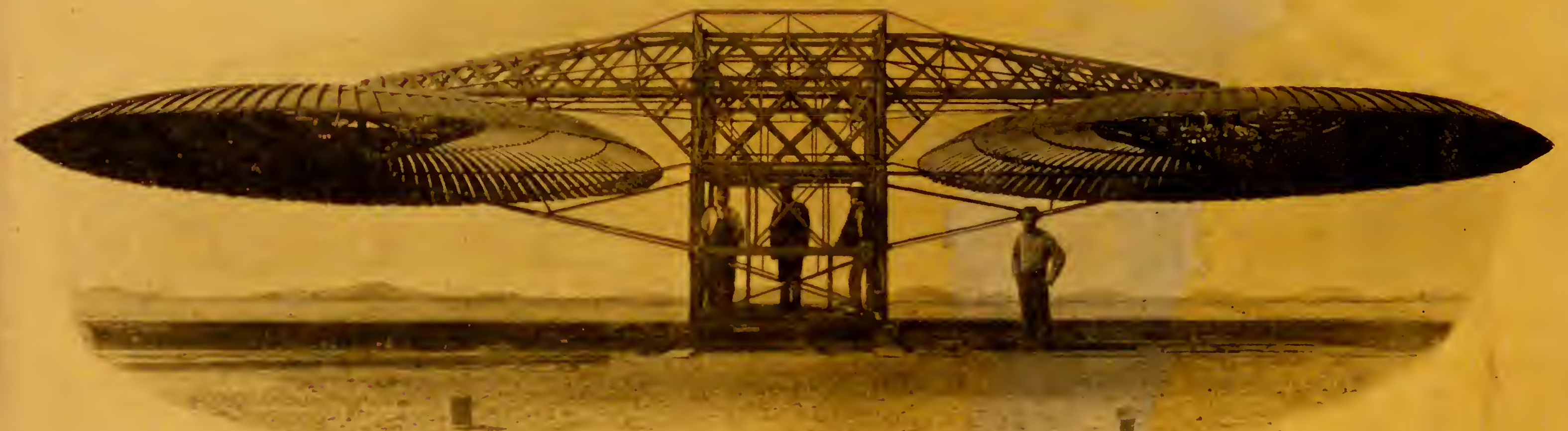

Photograph of the experimental Gyropter, or Rotary Wing Flying Machine taken during its construction.

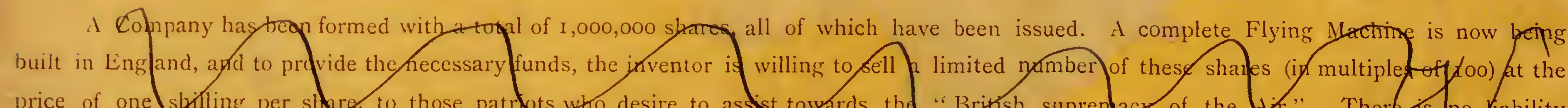
price of one sbriling per stere, to those patrtets who desire to asstat towards the "British suprentacy of the thi." Ther is no Irability on these shares.

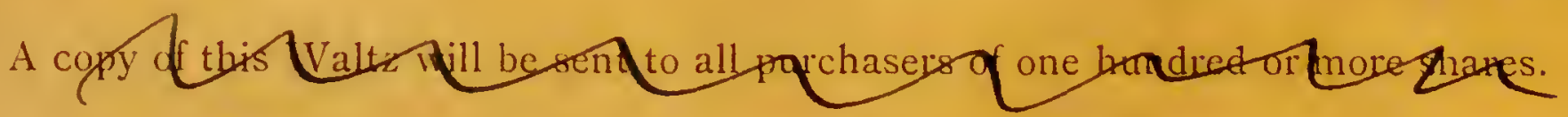

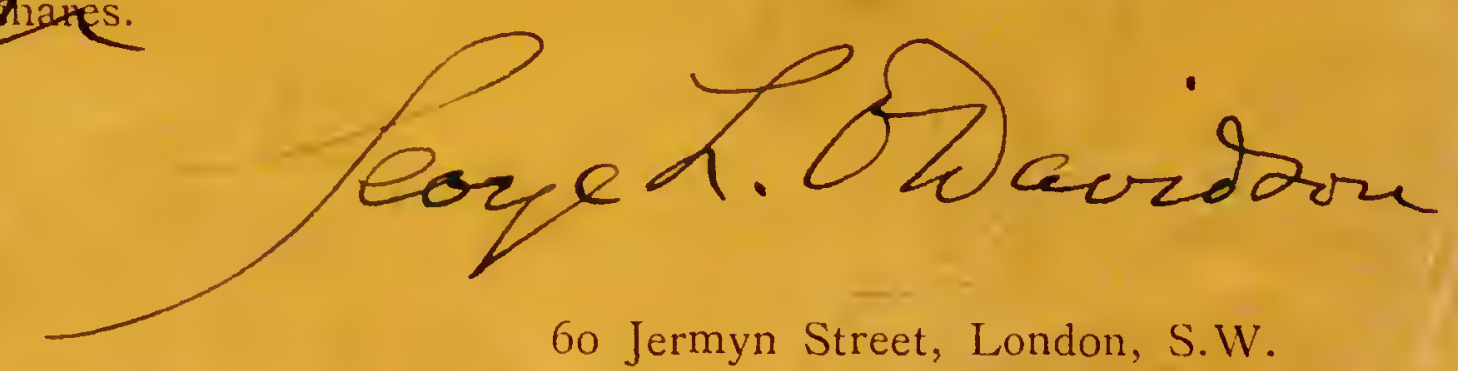





\section{FLYING-MACHINE VALSE.}

GEORGE L.O. DAVIDSON.

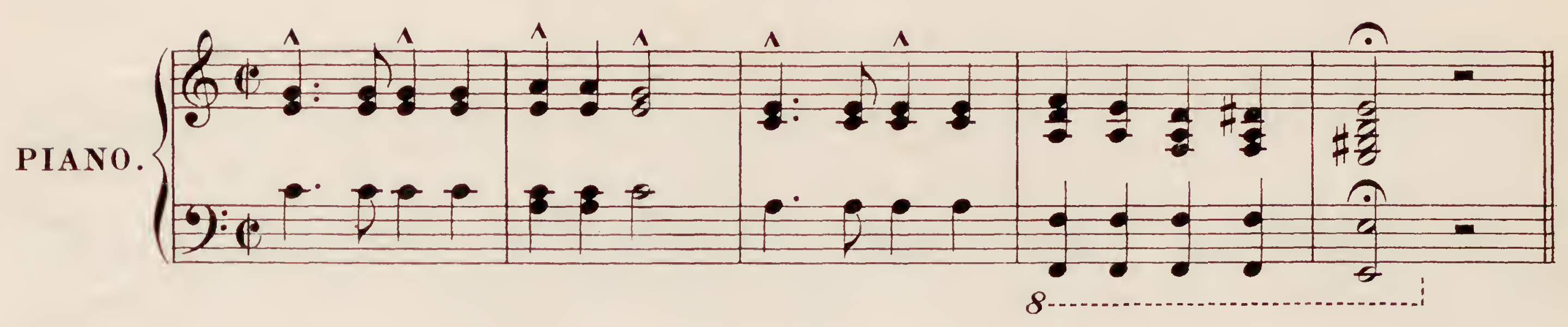

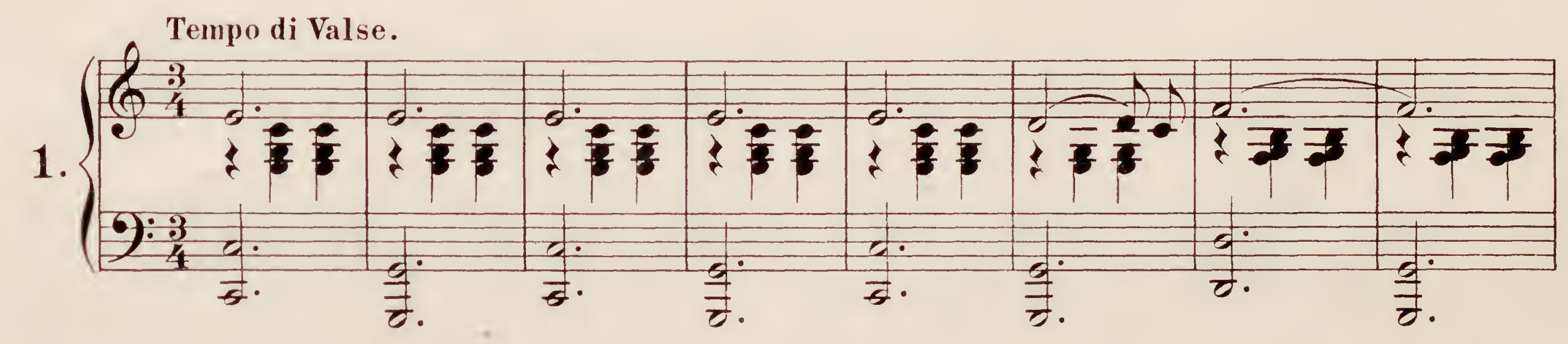
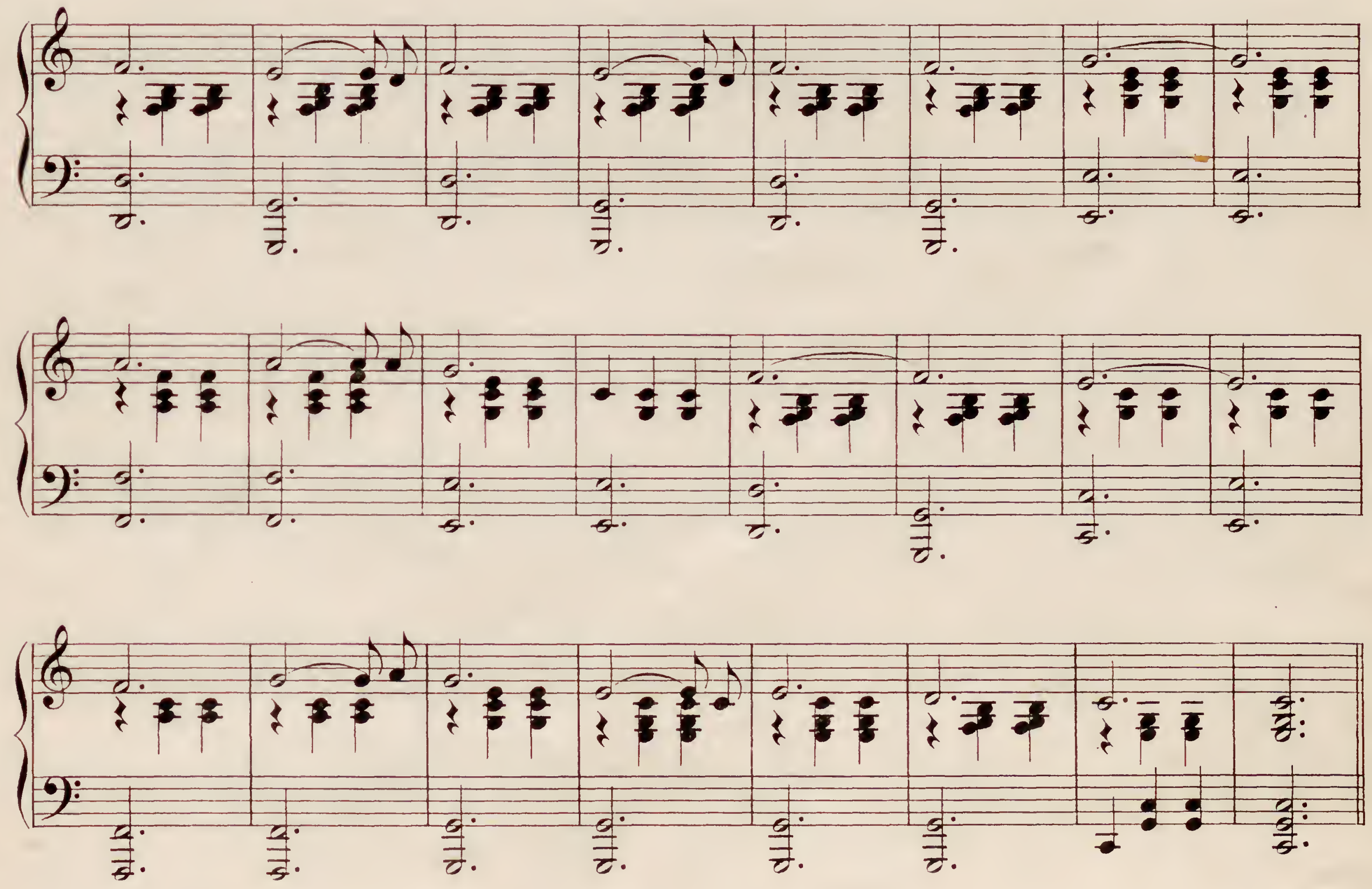


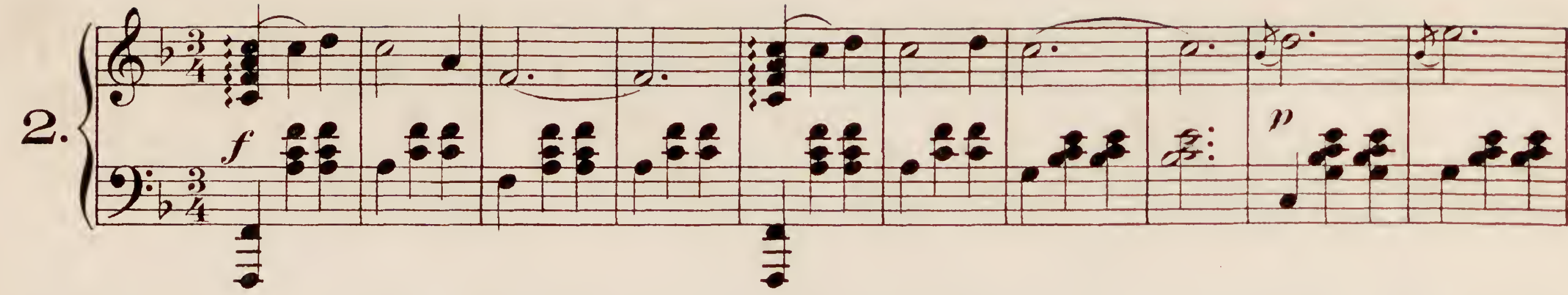

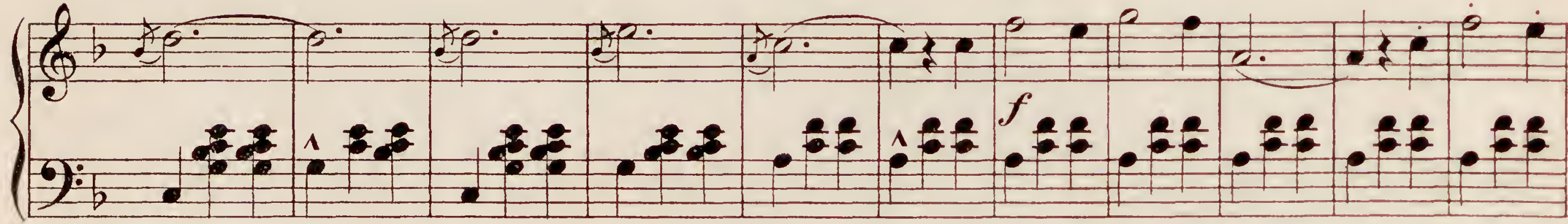
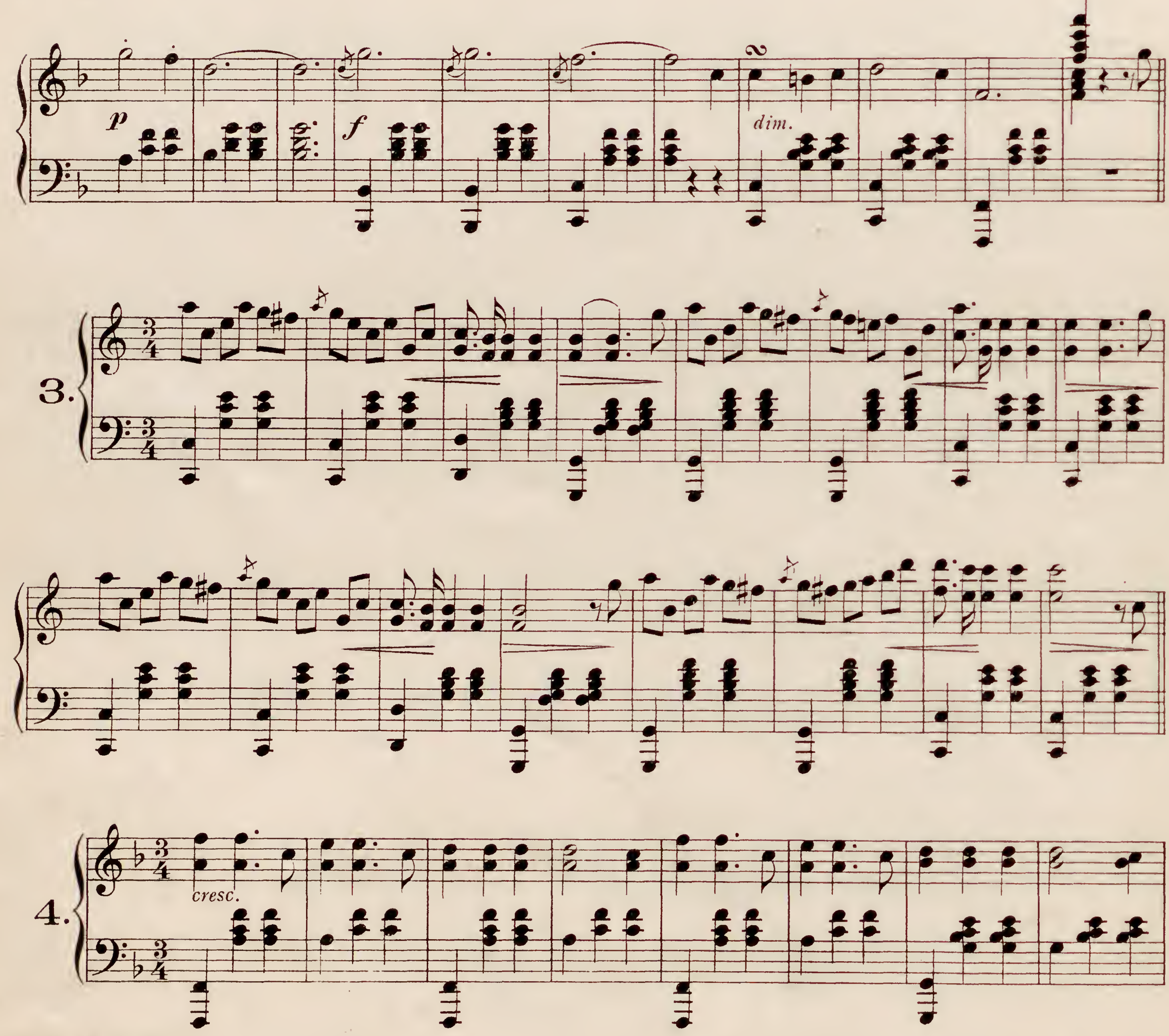

Flying-Machine Valse. 


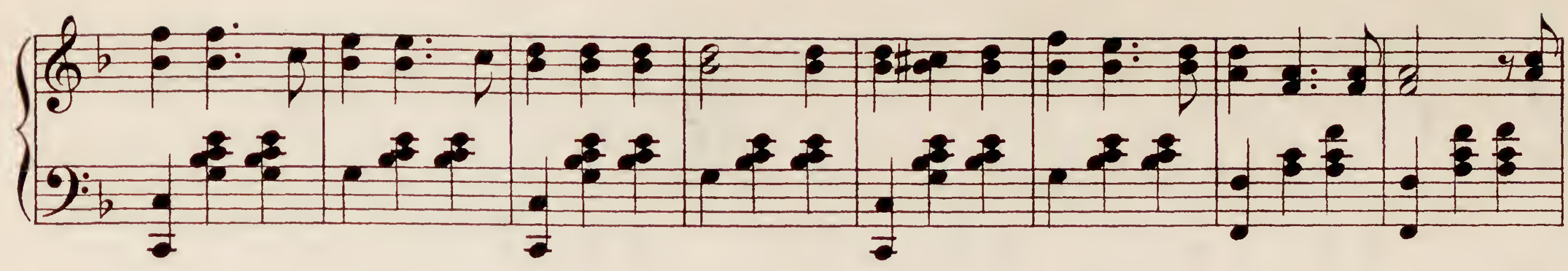

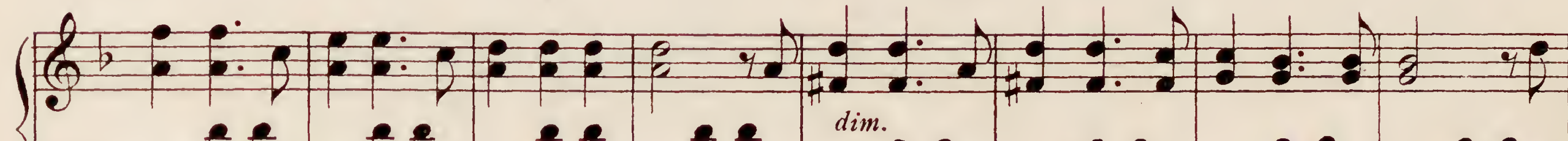

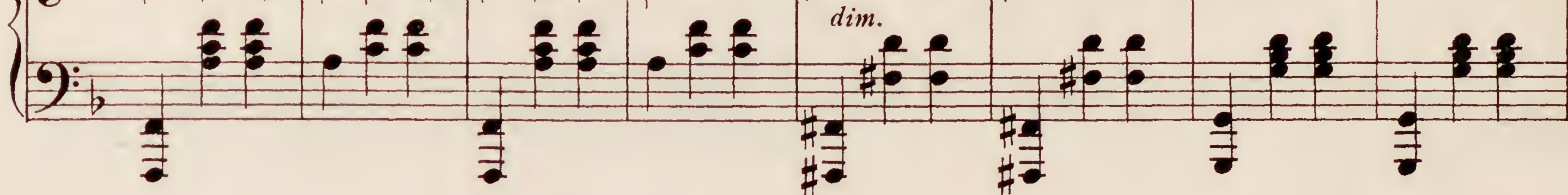

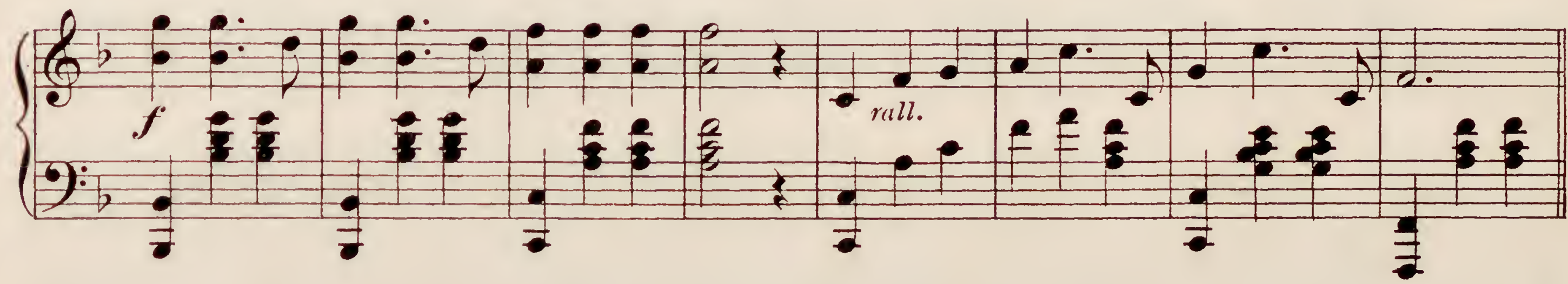

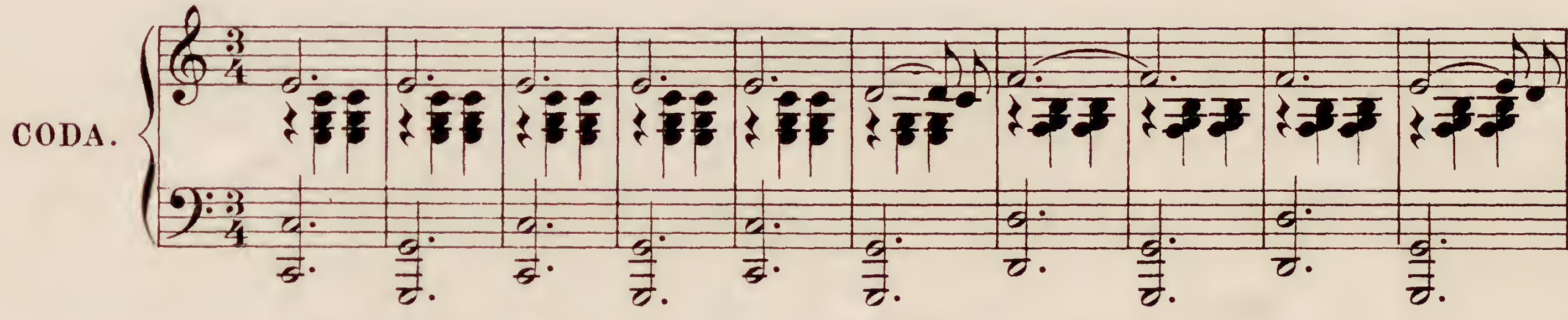

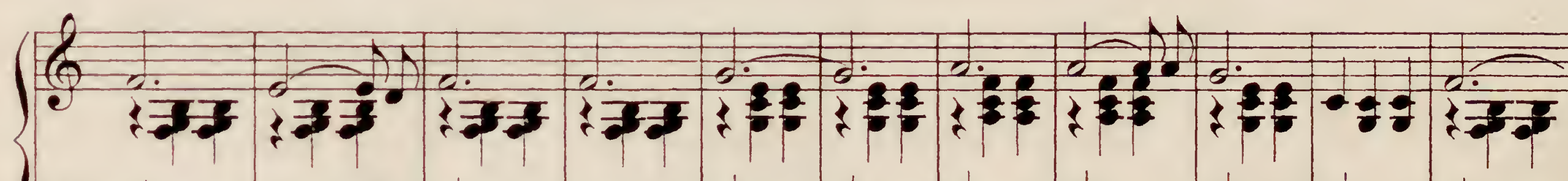

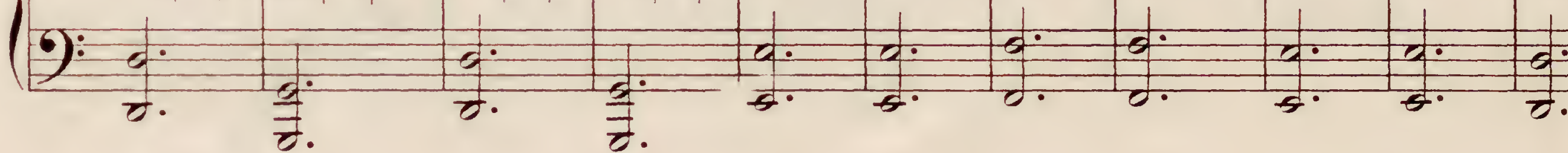

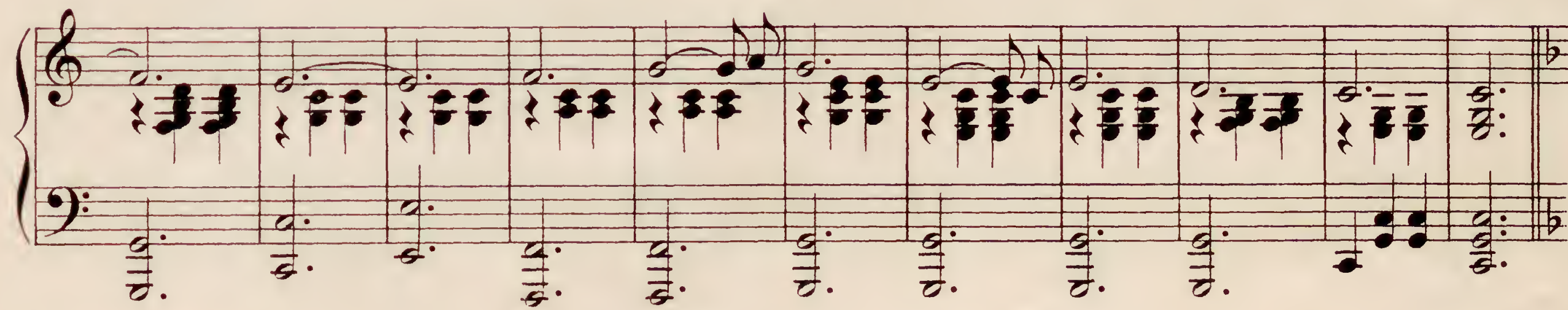
Flying-Machine Valse. 
4
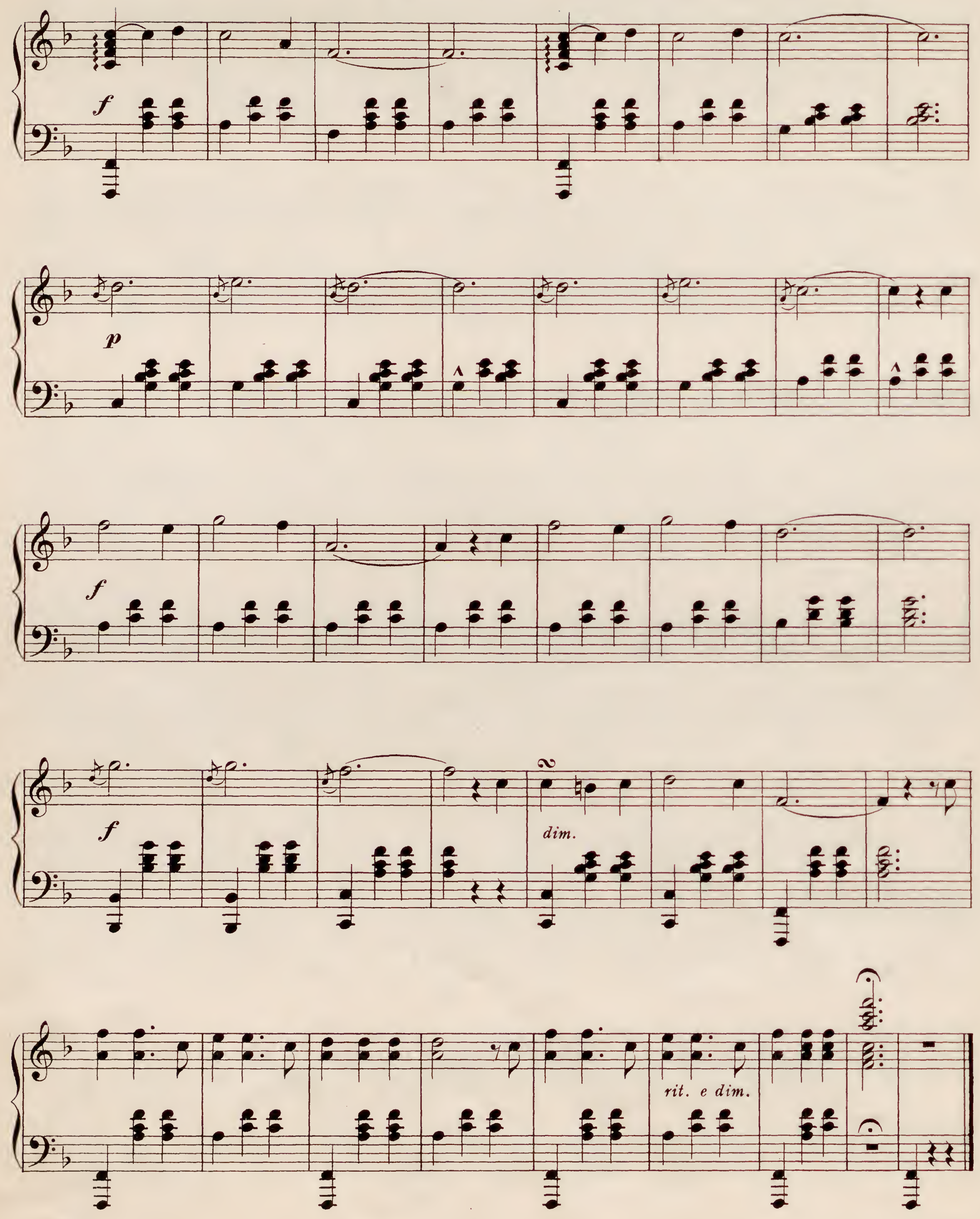

Flying-Machine Valse. 



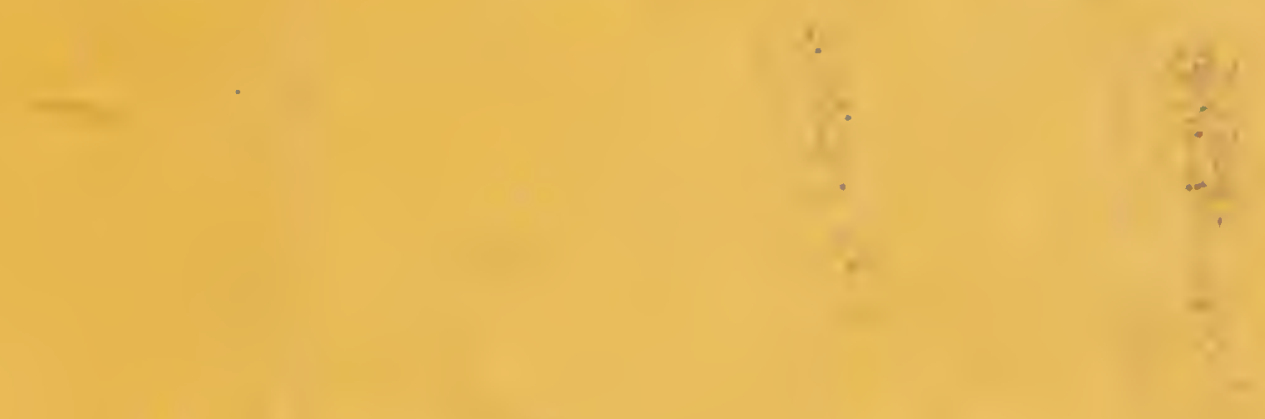

$=$

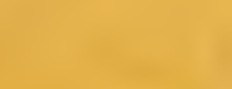

v
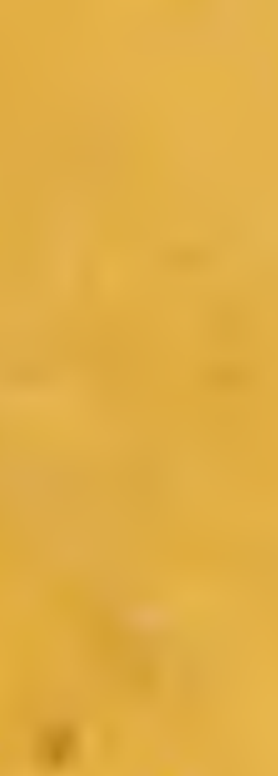